\title{
The Significance of Natural Computing for Considering Computational Aesthetics of Nature
}

\author{
Fuminori Akiba \\ Graduate School of Information Science, Nagoya University, Japan \\ akibaf@is.nagoya-u.ac.jp
}

\begin{abstract}
In this paper, I aim to propose computational aesthetics of nature and to explain how the idea of "harness" in natural computing is centrally important to this end. First, I reconfirm the original scope of Kant's aesthetics that is at the core of computational aesthetics. In the discussion of Kant's aesthetics, I contend that the reason Kant introduced the concepts of beauty in nature and aesthetic judgment into his philosophy is because he recognized them as key drivers behind the development and cultivation of our understanding of nature. I point out that the field of computational aesthetics presently understands Kant's aesthetics only insufficiently. There thus exists a need to propose another computational aesthetics of nature and to define its central aim: to find the beautiful in nature, leading us both to a better understanding of nature, and to a greater awareness of how we should live in nature. With this aim in mind, "harness" emerges as a useful tool for computational aesthetics of nature-one that merits consideration.
\end{abstract}

Keywords: aesthetics, computation, nature, Kant, harness, indirect interaction, tactile score.

\section{Introduction}

Since G.D. Birkhoff (1928), computational aesthetics (CA) has had a long history (Scha \& Bod 1993, Hoenig 2005). Correspondingly, there now exist multiple societies devoted to the research and promotion of CA, Computational Aesthetics in Graphics, Visualization and Imaging (CAe), and the International Society for Mathematical and Computational Aesthetics (IS-MCA) - the latter of which engages with a seemingly wide variety of topics and subfields (see the website of IS-MCA*).

In spite of a variety of topics, in their background we can easily find the strong echoes of a philosopher-Immanuel Kant (1724-1804). For example, IS-MCA website says "all design attempts to satisfy two constraints: functionality and aesthetics. Even a discipline as functionally oriented as structural engineering, in fact, involves aesthetic control over systems of non-linear equations". It easily reminds me one of famous ideas of Kant's aesthetics, "formal purposiveness" which I explain in 2.3 below.

Other researchers, explicitly or implicitly, also invoke Kant's aesthetics. "The best analysis of the esthetics [sic] is still Immanuel Kant's. He viewed experience of beauty 
as the consciousness of a psychological process: the pleasing awareness of harmony in the free play of our cognitive faculties" (Scha and Bod 1993). "Kant had also described aesthetics as a reinforcing supplement to logic ideas or concepts hinting that objects are higher value to us if they are beautiful" (Hoenig 2005). Bertelesen 2002 says "[T]he problem [of aesthetic computing] is the paradoxical one of meeting needs that don't yet exist, supporting the development of practice that we cannot yet imagine." The phrase "meeting needs that don't yet exist" or "supporting the development of practice that we cannot yet imagine" suggest correspondence to the key concept of Kant's aesthetics, "formal purposiveness" again.

Yet a number of CA scholars appear to unduly limit the ways in which Kant's aesthetics may be applied and understood. Hoenig (2005), for example, identifies essential questions: "Can we construct tools that assist with creating beauty as easily as they do now with purely functional development? Can we make machines aware of aesthetics in a similar fashion as humans are?" The narrow, "industrial" scope of the abovementioned questions is unsettling. IS-MCA is also concerned only with "design object", even though the idea of design object covers a wide variety of subjects ranging from "the machine-sculpted surface of a car body" to "the Feynman propagator in quantum electrodynamics."

The need for CA's rapid practical applicability to industrial design understandably promotes such a limited approach. However, is it the primary task of CA to help design beautiful artificial objects, which have aesthetic qualities beyond mere functionality, with computational methods? Is it the main task of aesthetics to develop supporting tools for designing such beautiful objects?

The answer to each of the above is probably "no," even though such tasks are significant. The scope of the field portended by Kant's aesthetics-a philosophical system inherently embedded in the understanding of computational aesthetics-is much wider. As we will see in the following sections, the reason why Kant introduced the ideas of beauty in nature and aesthetic judgment into his philosophy is because he recognized these two concepts as key drivers behind the development and cultivation of our understanding of nature. Of course, this is not to say that CA's present (limited) understanding of Kant's aesthetics is wrong; for, in fact, it does call on a part of Kant's aesthetics. However when we consider the entire scope of Kant's aesthetic theory, we realize that CA's present understanding of Kant's aesthetics is insufficient, and that we should propose another computational aesthetics of nature.

\section{The Scope of Aesthetics Suggested by Kant's Critique of the Power of Judgment}

Here I mention only basic points indispensable for recovering the wide-scope approach that I can derive from Kant's philosophical aesthetics. The basic points are as follows:

1) Kant introduced the idea of "purposiveness" as a principle of judgment in order to advance our understanding of nature (2.1); 
2) On the basis of a principle of purposiveness, "reflective judgment" advances our understanding of nature (2.2);

3) Aesthetic judgment, as a kind of reflective judgment, cultivates our interest in nature. Beauty and aesthetic judgment facilitate our understanding of nature (2.3);

4) In addition, beauty and aesthetic judgment also cultivate our moral feelings (2.4);

At the end of this section, I confirm the roles of the beautiful in nature and aesthetic judgment, and point out that CA's understanding of Kant's aesthetics is insufficient. Finally, I define the essential task of aesthetics different from presently accepted (2.5).

\subsection{The Principle of the Lawful Unity of Nature}

For Kant, the most important thing is to understand nature as mechanism. He assigned the role of advancing our understanding of nature to the faculty of judgment. Through the power of judgment (more precisely, what Kant deems our "determinant judgment"), we subsume a specific natural object before us under the laws of nature as mechanism. However, when the diversity or multiplicity of nature goes too far, it becomes harder for our judgment to determine under which specific laws the objects of nature before us should be subsumed. Judgment loses its way. Even when the differences between natural objects are perceived to be great, we must find higher laws that interconnect them, and thus continue to develop our understanding of nature. But how can we do so? This is at least one of the reasons Kant wrote his treatise, the Critique of the Power of Judgment. He tries to rescue judgment from such difficulty and gives another potent principle to judgment reflecting upon nature. It is a principle that holds the "lawful unity" of nature (Kant 70). We can assume that the great, confounding multiplicity nevertheless has unity under a few principles.

\subsection{A Principle of Purposiveness and Two Kinds of Judgment}

\subsubsection{A Principle of Purposiveness for Cognitive Faculties}

To this "lawful unity", Kant gives another name. He calls it "a principle of purposiveness for our faculty of cognition" (70-71), because if we are allowed to assume that nature contains a lawful unity, it is quite purposive for our cognitive faculties whose purpose is to improve our understanding of nature.

Under the guidance of this principle, the power of judgment tries to find "possible (still to be discovered)" (70-71) laws of nature. However, in this case, as he says, the principle is requested by judgment itself for its own guidance, for its own cognitive faculty, not for the sake of the object or objects before it. Therefore, Kant calls it the "subjective" principle of judgment.

\subsubsection{Two Principles and Two Kinds of Judgment Requested to Advance Our Understanding of Nature}

Here we recognize that there are two kinds of judgment. One is the kind of judgment that subsumes specific objects of nature under pre-established laws-what Kant calls a 
"determinant judgment," governed by a "constructive" principle. The other type of judgment is one which reflects upon nature without laws [and concepts], and tries to find possible (still discoverable) laws of nature. Kant dubs this "reflective judgment," operating under the "regulative" principle. On the basis of this classification, Kant defines the principle of purposiveness for the cognitive faculty as the regulative and subjective principle for "reflective" judgment. We utilize these two complementarily to advance our understanding of nature.

\subsection{The Status and the Role of Aesthetic Judgment}

As I have just remarked, one of the reasons Kant wrote his Critique of the Power of Judgment is to advance our understanding of nature. And it is in this context that he introduces aesthetic judgment. In order to realize the significance and the role of aesthetic judgment in this context, the following three points are important:

1) Aesthetic judgment is the purest form of reflecting judgment (see 2.3.1 below);

2) Aesthetic judgment has the same subjective condition as all judgments. However, in judging beauty in nature, our cognitive faculties stay in a state of free play without achieving practical ends and keep animating one other (2.3.2);

3 ) This animation resulting from judging beauty in nature facilitates our attention to nature. (2.3.3)

\subsubsection{Aesthetic Judgment Is the Purest Form of Reflective Judgment: A Principle of "Formal" Purposiveness for Cognitive Faculties}

As a kind of reflective judgment, it does not subsume natural objects under already established laws. However, in contrast to reflective judgments in general, it does not try to find a (still to be discovered) rule outside the judging subject. It relates natural objects only to the judging subject's feelings of pleasure or displeasure. The subjective feeling of pleasure or displeasure conditions the rule: If an object results in pleasure for someone who judges it, and satisfies him or her without any specific purpose, then the object is beautiful; if it does not, it is not beautiful.

As we have seen, reflective judgments in general rely on the principle of purposiveness, with the aim of improving our understanding of nature. In this sense, it relates the principle still to objects in nature. In contrast, aesthetic judgment relates it only to the feeling of pleasure. It completely lacks substantial aims. Kant thus describes this character of aesthetic judgment as "formal," the opposite of substantial, and thus deems the principle of aesthetic judgment as one which has as its basis the "formal purposiveness of nature." Aesthetic judgment contains a principle for reflecting upon nature in its purest form:

In a critique of the power of judgment the part that contains the aesthetic power of judgment is essential, since this alone contains a principle that the power of judgment lays at the basis of its reflection on nature entirely a priori, namely that of a formal purposiveness of nature in accordance with its particular (empirical) laws for our faculty of cognition, without which the understanding could not find itself in it... (79) 


\subsubsection{Aesthetic Judgment Has the Same Subjective Condition as All Judgments. However, in Judging the Beauty in Nature Our Cognitive Faculties Stay in a State of Animated Free Play without Achieving Practical Ends}

Kant says that, with regard to the representation of an object, the agreement of imagination and understanding is required as the subjective condition for all judgments.

The subjective condition of all judgments is the faculty for judging itself, or the power of judgment. This, employed with regard to a representation by means of which an object is given, requires the agreement of two powers of representation: namely, the imagination (for the intuition and the composition of the manifold of intuition), and the understanding [in German, Verstand] (for the concept as representation of the unity of this composition). (167)

Concerning aesthetic judgment the subjective condition is the same. However, there is a significant difference. Normally, understanding dominates imagination and unifies the manifold of intuitions given by imagination into the concept given by understanding. In contrast, when judging the beautiful in nature, imagination does not obey understanding. They mutually animate one another, because aesthetic judgment lacks any laws, under which the object should be subsumed, and any concepts, under which the manifold of intuition should be united. Kant writes:

[S]ince the freedom of the imagination consists precisely in the fact that it schematizes without a concept, the judgment of taste [i.e., aesthetic judgment] must rest on a mere sensation of the reciprocally animating imagination in its freedom and the understanding with its lawfulness, thus on a feeling that allows the object to be judged in accordance with the purposiveness of the representation (by means of which an object is given) for the promotion of the faculty of cognition in its free play... (167), italic by Akiba

In short, aesthetic judgment is judgment which arises from the minimum subjective condition of all judgments, and which animates itself through the act of judging the subjective purposiveness of the representation before it.

\subsubsection{The Animation of Our Cognitive Faculties in Judging the Beauty in Nature Facilitates Our Attention to Nature}

Consequently, the more variation the representation contains, the more lasting this animation. And the thing that contains the widest variety in the world is, of course, nature. Therefore, aesthetic judgment is inevitably fascinated by nature: “...[N]ature, which is there extravagant in its varieties to the point of opulence, subject to no coercion from artificial rules, could provide his taste with lasting nourishment" (126). In judging "a free and indeterminate purposiveness" of the natural objects, "the mental powers" (i.e., understanding and imagination) are entertained "with that which we call beautiful" (123).

In this way the beautiful in nature-and aesthetic judgment, which is fascinated by it - cultivate our interest in nature and make us attentive to it. It is also important that Kant thinks the beautiful in nature "cultivates a certain liberality in the manner of thinking" (as below) because it brings us a possibility to see nature in a different way: 
"The beautiful prepares us to love something, even nature, without interest...the beautiful in nature likewise presupposes and cultivates a certain liberality in the manner of thinking, i.e., independence of the satisfaction from mere sensory enjoyment, nevertheless by means of it freedom is represented more as in play than as subject to a lawful business..."(151)

To briefly summarize the discussion above: in order to advance our understanding of nature, Kant introduces two different but complementary principles. One is a so-called constructive principle for determinant judgment, and the other is a regulative principle for reflective judgment, that is, a principle of purposiveness. On the basis of the latter principle, the power of aesthetic judgment judges the beautiful in nature and cultivates our interest in the diversity of nature. Thus, beauty and aesthetic judgment play significant roles as motivators, or rather cultivators, of our understanding of nature (Table 1).

Table 1. Classification of judgment in Kant's Critique of the Power of Judgment

\begin{tabular}{|c|c|c|c|c|c|}
\hline \multicolumn{2}{|l|}{ judgment } & its principle & is related to & its role & \begin{tabular}{|l} 
its view of \\
nature
\end{tabular} \\
\hline \multicolumn{2}{|c|}{ determinant } & mechanism & \begin{tabular}{|l} 
object(s) in \\
nature
\end{tabular} & constructive & mechanical \\
\hline \multirow[t]{2}{*}{ reflective } & $\begin{array}{l}\text { reflective } \\
\text { in general }\end{array}$ & purposiveness & $\begin{array}{l}\text { the subject, } \\
\text { but } \\
\text { indirectly to } \\
\text { object(s) in } \\
\text { nature }\end{array}$ & regulative & teleological \\
\hline & aesthetic & $\begin{array}{l}\text { subjective/ } \\
\text { formal } \\
\text { purposiveness }\end{array}$ & $\begin{array}{l}\text { subjective } \\
\text { feelings }\end{array}$ & facilitative & $\cdots$ \\
\hline
\end{tabular}

\subsubsection{Beauty and the Moral Value}

One more thing we must not forget is that Kant assumes a strong relationship between the beauty of nature and moral value. Kant makes the assertion "that to take an immediate interest in the beauty of nature [...] is always a mark of a good soul, and that if this interest is habitual, it at least indicates a disposition of the mind that is favorable to the moral feeling, if it is gladly combined with the viewing of nature" (178).

The principle of purposiveness is also the principle of teleological judgment. By this principle, we assume that nature organizes itself as if it prepares for the realization of a final purpose [telos], that is, the realization of moral goodness. This assumption is supported by the existence of organisms that produce themselves as if they had a purpose in and of themselves, and by the existence of human beings who are obliged to realize a final purpose in the world. Beauty in nature and aesthetic judgment, through the principle of purposiveness that they share with teleological (moral) judgment, make us attentive to such moral values. 


\subsection{CA Understands Kant's Aesthetics Partially, But Insufficiently}

CA's understanding of Kant's aesthetics is not wrong because it does, in fact, depend upon a part of Kant's aesthetics. However, given the entire scope of Kant's aesthetics as discussed above, current CA's understanding of Kant's aesthetics is insufficient because it is not inclusive of the fact that Kant recognizes beauty in nature and the power of aesthetic judgment as cultivators, which further the development of our understanding of nature and its moral values. Therefore, we should propose another computational aesthetics of nature.

\subsection{The Essential Task of Computational Aesthetics of Nature}

From what we have discussed above, we may say that:

1) Beauty must facilitate our understanding of nature;

2) At the same time, it must facilitate our moral feelings, in other words, make us aware of how we should live in nature.

It does not matter at all whether such beauty takes the form of artwork or designed objects.

In this light, we also must return to the definition of aesthetics of nature. Aesthetics of nature is the science of beauty in nature. And the essential task of aesthetics of nature is to find beauty in nature which advances our understanding of nature and which makes us aware of how we should live in nature. In order to achieve this aim, aesthetics of nature utilizes two different principles. One is a scientific (mechanical) principle. The other is a complement to it. If computational aesthetics is to be any kind of aesthetics at all, it must succeed in using these principles to find beauty in nature.

\section{Natural Computing and Its Significance for Computational Aesthetics of Nature}

From this standpoint, natural computing (NC) — and its concept of "harness" — shows the direction in which CA must turn, because NC does not only aim to make artificial things, but also to advance our understanding of nature through computing.

\subsection{Two Ideas of Computation and the Idea of "Harness"}

\subsubsection{Two Ideas of Computation: Constructive and Oracle}

$\mathrm{NC}$ emerges as highly important because it is an approach that uses two different ideas of computation in order to advance natural science: "constructive computation" and "oracle computation." The constructive type refers to when we can explicitly show every step of an algorithm. Oracle computation, by direct contrast, describes when we cannot explicitly show every step of an algorithm (Suzuki 2009), such as is the case with Physarum computation. 
Table 2. Two ideas of computation: constructive and oracle

\begin{tabular}{|l|l|l|}
\hline computation & its algorithm & its representative \\
\hline constructive & explicit & TM (Turing machine) \\
\hline oracle & implicit & DNA, Physarum \\
\hline
\end{tabular}

In the following, we introduce the idea of "harness" in NC and its relationship to these two kinds of computation, and then we point out its significance for the project of computational aesthetics of nature.

\subsubsection{The Idea of "Harness"}

In its original sense, the word "harness" means "a set of strips of leather and metal pieces that is put around horse's head and body so that the horse can be controlled and fastened to a carriage, etc." (Oxford Advanced Dictionary). In its more general usage, the term has come to represent the way human beings have corralled and utilized natural forces to perform work.

In the sphere of NC, the word "harness" ' is used in a slightly different way. It simply denotes alternate means of control. We shall explain it by way of comparison with the traditional method of control. With the traditional control method, we strictly limit the boundaries of a system and directly manage its given inputs and outputs. In order to do so, we must know every step of the system, one by one. Let us call this the "direct" type of control. Consider, however, that a shepherd walking with a picture of a wolf in his hands can move a flock of sheep to the pen. There is no need to know every detailed mechanism of the process, no need to manage each sheep directly and individually, and no need to set strict boundaries. The only one thing the shepherd must know is the fact that he can move a natural system (in this case, a flock of sheep) with an artificial thing (in this case, a picture of a wolf). This is what may be dubbed the "indirect" type of control, which corresponds to the idea of the "harness."

Take a tritrophic [plants-harmful insects (herbivores)-natural predators (carnivores)] ecosystem as another example. From the perspective of direct control, the best way to avoid harmful insect damage in this system is to launch direct attacks against the perpetrating insects with agrochemicals. However, this unnatural extinction completely destroys the balance of the ecosystem. Therefore, if nonnative insects that locally lack natural predators enter the picture, the entire ecosystem dies. On the contrary, nature does not do such foolish things. It utilizes indirect control via what are called Herbivore Induced Plant Volatiles (HIPVs) to regulate interactions between plants, insects, and predators. When insects eat plants, plants produce HIPVs that act as signals to natural predators (such as birds) that their prey is close at hand. Because of this indirect system of control, the ecosystem can avoid unnecessary extinctions and sustain stable diversity. It is completely different from direct control methods, which can effect local and total extinctions, and from direct food chain systems, which can often result in unstable population changes (see Suzuki and Sakai 2012 in this volume). 
If we can imitate the indirect interactions inherent to the natural system-in other words, if we can harness the natural system-we can contribute to sustaining its diversity. However, in order to do so, we must know about the existence of such indirect interactions in nature, know what factors drive the interactions, and know how to construct information pathways such as the one modeled above in the HIPVs example.

\subsubsection{The Idea of Harness Encourages Us to Find Possible (Still Discoverable) Indirect Interactions in Natural Systems: Harness and Two Kinds of Computation}

Consequently, the idea of harness requires us to study natural systems because we need to find possible (still discoverable) indirect interactions in natural systems. It promotes our understanding of nature. However, we do not have to know every detailed algorithm of a given natural system. Nature is so complex that we may never know every step to its processes. In this sense, natural systems remain examples of oracle computations. However, if we successfully find accessible points, such as are represented by HIPVs, that enable us to understand and operate indirect interactions, we can glean clues towards comprehending the overall oracle computational system. We can thereby construct artificial materials and insert them into natural systems.

Now we can define the idea of harness more precisely, from the perspective of computation. Harness provides an alternate means of control that operates oracle computations by using the products of "constructive" computations. On the basis of this idea, researchers in the field of NC study, for example, the modifications of influenza and info-chemical signals in chemical ecology (see articles in this volume).

\subsubsection{The Significance of Harness for Aesthetics of Nature}

Probably the reader has already noticed that there are correspondences between the idea of harness in NC and aesthetics of nature. Firstly, the concept of harness in NC advances our understanding of nature. In addition, it facilitates our moral or ethical feelings for nature. As we have just seen above, in the idea of harness we find a clear sense of moral (or ethical) duty to "sustain the diversity in natural systems." From these two points, it follows that the idea of harness in NC suggests a desirable direction for the discipline of computational aesthetics of nature.

\subsection{Human Nature and the Harness Concept in NC}

At the end of this paper, we briefly mention research on human nature from the standpoint of the harness concept in NC. If harness is an attempt to operate oracle computations through constructive computations on the basis of (still to be discovered) interactions, it can be likewise applicable to the mysterious systems which comprise human nature.

\subsubsection{Massage and Tactile Score}

The tactile sense, or sense of touch, is a sense for which the sciences still have not provided sufficient explanations. Of course, we all know from numerous reports that massages (offering stimulation via the tactile sense) often relieve various disorders, for 
example, skin disorders. A multitude of studies have tried to make clear what makes such relief possible. Yet unfortunately, we still do not have enough evidence regarding the matter -it corresponds to oracle computation-. And the algorithm of interaction between touching and touched still remains implicit. If we could find some necessary (still to be discovered) access points in the interactions between touching and touched, and if we could operate the interaction by way of accessing these points, then we could give assistance to people suffering from certain disorders.

In relation to this point, a significant project is underway concerning tactility. It invents the concept of a "tactile score," and through scientific analysis, gradually reveals the existence of formal structures of massages (Suzuki, Watanabe, \& Suzuki 2012). In the future, it might be possible for us to find accessible points in these structures. Those people who misunderstand massages as the stuff of hedonism and think of them not as the subject of aesthetics, do not understand the scope of Kant's aesthetics - even though they may believe that they depend on Kantian formalist aesthetics.

\subsubsection{Media through Which We Become Aware of Our Nature and How to Live with Them}

Just as the tactile score tries to reveal what is behind our sense of touch, and tries to make us think how should we use it, certain media attempt to clarify principles of human nature and to determine how we should transform our lives accordingly. For example, Saccade-based Display (Ando \& Watanabe) is a medium which brings us such experiences as "consist of deterministic information systems aimed for triggering perceptual experience, which can open up questions about what human beings are, and why they perceive in such ways" (Watanabe 2012, see also his article in this volume, Cf. Akiba 2003). From this point of view we can reinterpret "designed objects" in the field of existing CA, and learn many things for the development of computational aesthetics of nature.

\section{Conclusion}

The reason why Kant introduced beauty in nature and aesthetic judgment in his philosophy is because he recognizes them as cultivators behind the development of our understanding of nature. Given the entire scope of his aesthetics, current computational aesthetics is insufficient and we must propose another computational aesthetics of nature. Its task should be to find the beautiful in nature-a pursuit which leads both to a better understanding of nature, and to a greater awareness of how we should live in nature. From this perspective, we can appreciate the notion of harness in the practice of $\mathrm{NC}$ as a worthwhile pursuit in furtherance of this end, and a signpost that signals a desirable direction for computational aesthetics.

Acknowledgement. This work was supported by JSPS KAKANHI Grant Number $21520133 \& 24520106$. 
Open Access. This chapter is distributed under the terms of the Creative Commons Attribution Noncommercial License, which permits any noncommercial use, distribution, and reproduction in any medium, provided the original author(s) and source are credited.

\section{References}

Akiba, F.: Information and Expression. Selected Papers of the 15th International Congress of Aesthetics, Makuhari, pp. 3-6 (2003)

Bertelsen: Aesthetics as Means for Supporting Development in Use - Beyond the Designed Purposefulness. In: Bertelsen, O., Fishwick, P. (eds.) Aesthetic Computing, Dagstuhl Seminar Report No. 348, http: / /www. dagstuhl. de/Reports/02/02291.pdf

Hoenig, F.: Defining Computational Aesthetics. In: Neumann, L., Sibert, M., Gooch, B., Purgathofer, W. (eds.) Computational Aesthetics in Graphics, Visualization and Imaging, Eurographics Digital Library (2005), http: / diglib.eg .org

IS-MCA (September 20, 2010), http: / /www.rci.rutgers.edu/ mleyton/ISMA.htm

Kant, I.: Critique of the Power of Judgment (1790); trans. Guyer, P., Matthews, E.: Cambridge University Press (2001)

Scha, R., Bod, R.: Computational Esthetics. In: Informatie en Informatiebeleid 11(1), pp. 54-63 (1993) http: / / iaaa.nl/rs/compestE.html

Suzuki, Y.: Self-Organization is Computation. In: Handbook of Self-Organization, S.T.N. (2009) (in Japanese)

Suzuki, Y., Watanabe, J., Suzuki, R.: Tactile Score, a Knowledge Media of Tactile Sense for Creativity. In: Watanabe, T., Watada, J., Takahashi, N., Howlett, R.J., Jain, L.C. (eds.) Intelligent Interactive Multimedia: Systems \& Services. SIST, vol. 14, pp. 579-587. Springer, Heidelberg (2012)

Watanabe, J.: An Interpretation of New Media Experiences Motivated by the Viewpoint of Computational Aesthetics. In: Proceedings of 6th International Workshop on Natural Computing (JSAI 2011) (2012) 